\title{
OP49
}

\section{A DATA-DRIVEN COLORIMETRIC ANALYSIS OF THE CIE STANDARD GENERAL SKIES}

\author{
Aicha Diakite et al. \\ DOI 10.25039/x46.2019.OP49 \\ from \\ CIE x046:2019 \\ Proceedings \\ of the \\ 29th CIE SESSION \\ Washington D.C., USA, June 14 - 22, 2019 \\ (DOI 10.25039/x46.2019)
}

The paper has been presented at the 29th CIE Session, Washington D.C., USA, June 14-22, 2019. It has not been peer-reviewed by CIE.

(C) CIE 2019

All rights reserved. Unless otherwise specified, no part of this publication may be reproduced or utilized in any form or by any means, electronic or mechanical, including photocopying and microfilm, without permission in writing from CIE Central Bureau at the address below. Any mention of organizations or products does not imply endorsement by the CIE.

This paper is made available open access for individual use. However, in all other cases all rights are reserved unless explicit permission is sought from and given by the $\mathrm{CIE}$.

CIE Central Bureau

Babenbergerstrasse 9

A-1010 Vienna

Austria

Tel.: +4317143187

e-mail: ciecb@cie.co.at

www.cie.co.at 


\title{
A DATA-DRIVEN COLORIMETRIC ANALYSIS OF THE CIE STANDARD GENERAL SKIES
}

\author{
Diakite, A.K. ${ }^{1}$, Knoop, M. ${ }^{1}$ \\ ${ }^{1}$ Technische Universität Berlin, Chair of Lighting Technology, Berlin, GERMANY \\ aicha.diakite@tu-berlin.com
}

DOI $10.25039 / \times 46.2019 .0 P 49$

\begin{abstract}
This paper studies the colorimetric characteristics of daylight within the framework of the CIE Standard General Skies. The correlated colour temperatures (CCTs) were studied based on long-term measurements. The colorimetric analysis employed in this study comprises: (i) the CCT occurrence; (ii) the CCT ranges; (iii) the CCT variation depending on the solar altitude; in function of season, time of day, and orientation, all corresponding to the fifteen CIE Standard Skies. The last part of the analysis illustrates the practical application of the results in the urban structure, represented in spectral daylight potential diagrams. The findings show significant colorimetric discrepancies both between and within the sky types and support the key argument against a fixed CCT for all sky types. The paper helps to understand the spatio-temporal variability of the CCT and indicates what possible effect that variation might have on the colorimetric daylight characteristics on façades, and therefore on the potential of a building regarding the ipRGC influenced responses to light.
\end{abstract}

Keywords: colorimetry, spectral sky measurements, CCT variability, daylight

\section{Introduction}

According to CIE S 014-2/E:2006 ISO 11664-2:2007(E) the standard illuminant D65 is meant to serve as 'an average daylight' and is to be used 'in all colorimetric calculations requiring representative daylight'. Although the variability in the relative SPD of daylight caused by the seasonality, the time of day, and the geographic location is recognised in CIE S 014-2/E:2006 ISO 11664-2:2007(E), for practical application it is still recommended to use D65 due to the lack of information on these variations. While there is a substantial amount of papers published in recent years on the non-uniformity of the luminance of the sky, relatively little appears to be written on its colorimetric distribution. Individual studies addressed the colorimetric variability of daylight, defining the mean CCT or dominant CCT interval depending on such factors as: the season and the time of day (Collins 1965), the solar altitude (Hernández et al. 2001-2), the scattering angle (Hernández et al. 2001-1), the atmospheric conditions (Peyvandi et al. 2016), the orientation (Henderson et al. 1964, Collins 1965), the geographic location (Sastri et al. 1971) and the sky type (Rusnák 2014). However, in the majority of those studies the variations are not related to a specific sky type and the factors affecting the variation are mostly addressed separately. Further, the measurements of the colorimetric properties of daylight were predominantly conducted globally, either horizontally or tilted facing the north sky, which makes an analysis of the direction dependence of the CCT difficult if not impossible. However, a few studies indicate a wide range of colour variation within a sky type without a clearly dominant region, particularly in clear skies, when measured spatially resolved (Rusnák 2014, Diakite et al. 2018). The studies indicate that the assumption of one CCT describing a whole sky for all sky conditions is incorrect. Additionally, a recent review of the existing data-driven spectral sky models conducted by the authors, building upon the correlation between CCT and luminance, revealed substantial discrepancies in the forecast for clear sky conditions (Diakite et al. 2019). The study suggested that further diurnal and seasonal parameters affecting the spectral distribution and therefore the CCT, need to be examined. Thus, to correctly address the colorimetric non-uniformity within a sky type this paper investigates in a holistic approach the colorimetric characteristics within the framework of the CIE Standard Skies classified by CIE S 011/E:2003. The aim of this work is threefold: (i) to understand the temporal and spatial variability of the correlated colour temperature (CCT); (ii) to estimate the colorimetric characteristics of the CIE Standard Skies; (iii) to indicate what possible implication the 
colorimetric variation might have on the spectral daylight characteristics on façades. Daylight plays a crucial role in many applications. The spatio-temporal variability of its intensity and colour is critical for smart, healthy and energy efficient daylighting strategies to enhance the visual and ipRGC influenced responses to light. Given the increasing significance of the ipRGC influenced responses to light (IIL), it has become all the more important to characterize the colorimetric variability of daylight appropriately. In our research, this is represented by means of the direction-dependent averaged CCTs, utilised in data-driven spectral sky models and spectral daylight potential diagrams (SDPDs), to improve the forecast accuracy of these IIL effects. The data-driven analysis of the CIE skies proposed in this paper is therefore an important step towards a better understanding of the spatial and temporal variations of the colorimetric characteristics of daylight and the implication of these changes on the urban level.

\section{Methods}

The study draws upon spatially and temporally resolved spectral power distribution measurements, collected over a period of twelve months. A set of over 16 million CCTs derived from these measurements is used to analyse the colorimetric characteristics of daylight.

\subsection{Experimental set-up}

The spatially and temporally resolved spectral daylight measurements have been carried out with a spectral sky scanner located in Berlin $\left(52^{\circ} 31^{\prime} \mathrm{N}, 13^{\circ} 20^{\prime} \mathrm{E}\right.$, altitude $\left.50 \mathrm{~m}\right)$. The adopted maximum time frame for each measurement was set to one minute. The subdivision of the sky hemisphere resulted in 145 sky patches. The spectral power distribution (SPD) was measured within an aperture angle of $10^{\circ}$, for a bandwidth of $280 \mathrm{~nm}-980 \mathrm{~nm}$ with a step size lower $1 \mathrm{~nm}$. For the analysis the bandwidth of $380 \mathrm{~nm}-780 \mathrm{~nm}$ was used. The measurements were carried out every second minute. The CCTs and luminances were subsequently derived from the spectral radiance measurements of skylight without direct sunlight. Exemplary luminance and CCT distributions showed in Figure 1 are available for download upon request at www.li.tuberlin.de. The CIE sky types were established based on the use of gradation and indicatrix groups. The device characterisation process is described in Knoop et al. (2017).
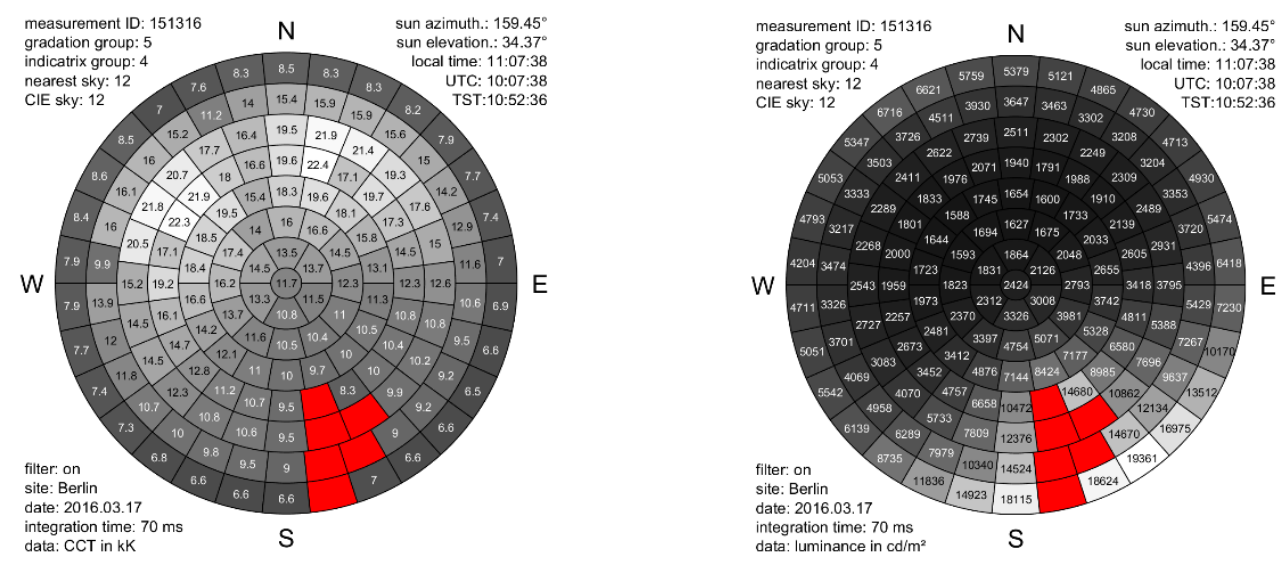

Figure 1 - Exemplary luminance and CCT distributions for a clear sky; Berlin 17 March 2016.

\subsection{Colorimetric analysis}

The colorimetric analysis employed in this study comprises: (i) the CCT frequency distribution of occurrence; (ii) the CCT ranges; (iii) the CCT variation depending on the solar altitude; all corresponding to the fifteen CIE Standard Skies. The analysis uses the inverse CCT (in reciprocal megakelvin) in $5 \mathrm{MK}^{-1}$ intervals, ranging from $0-200 \mathrm{MK}^{-1}$. The scheme of the analysis is summarised in tabular form in Table 1 . In the analysis of the CCT occurrence and CCT ranges only datasets for a solar altitude higher $15^{\circ}$ were taken into consideration (Knoop et al. 2019). The last part of the analysis illustrates the practical application of the results in the urban structure. The statistical analysis encompasses two exemplary SDPDs to highlight the colorimetric ranges on vertical planes in the urban structure depending on prevailing sky conditions and building orientation in $1^{\circ}$ resolution. The methodology to create the SDPDs is presented in Diakite et al. 2018. 
Table 1 - Analysis scheme

\begin{tabular}{|c|c|c|c|c|c|}
\hline Analysis & CIE sky type & Period of time & Orientation & Time of day & Results in \\
\hline $\begin{array}{l}\text { CIE sky type } \\
\text { occurrence }\end{array}$ & CIE 1-15 & $\begin{array}{c}01.01 .2015- \\
31.12 .2015 \\
(2015) \\
\\
01.06 .2015- \\
31.08 .2015 \\
\text { (Summer 2015) } \\
\\
01.01 .2015- \\
31.03 .2015 \\
\text { (Winter 2015) }\end{array}$ & $\begin{array}{l}\text { Patches from the } \\
\text { whole hemisphere } \\
\text { except the 1st } \\
\text { almucantar (Patch } \\
31-145)\end{array}$ & $\begin{array}{l}\text { every hour } \\
\text { (in UTC) }\end{array}$ & Figure 2 \\
\hline \multirow[t]{5}{*}{$\begin{array}{l}\text { CCT frequency } \\
\text { distribution of } \\
\text { occurrence }\end{array}$} & $\begin{array}{c}\text { No } \\
\text { differentiation } \\
\text { between sky } \\
\text { types }\end{array}$ & $\begin{array}{c}2015 \\
\text { Summer } 2015 \\
\text { Winter } 2015\end{array}$ & $\begin{array}{l}\text { Patch } 31-145 \\
\text { Patches from the } \\
\text { north part of the } \\
\text { hemisphere }(N) \\
\text { Patches from the } \\
\text { south part of the } \\
\text { hemisphere (S) }\end{array}$ & $\begin{array}{l}\text { UTC: } \\
\text { 9:00 a.m. } \\
\text { 12:00 p.m. } \\
\text { 3:00 p.m. }\end{array}$ & Figure 3 \\
\hline & CIE 1-15 & 2015 & Patch 31-145 & $\begin{array}{l}\text { every hour } \\
\text { (in UTC) }\end{array}$ & Figure 4 \\
\hline & CIE 3:9:12 & $\begin{array}{l}\text { Summer } 2015 \\
\text { Winter } 2015\end{array}$ & Patch 31-145 & $\begin{array}{l}\text { every hour } \\
\text { (in UTC) }\end{array}$ & Figure 5 \\
\hline & CIE 3:9:12 & Summer 2015 & $\begin{array}{l}N \\
S\end{array}$ & $\begin{array}{l}\text { every hour } \\
\text { (in UTC) }\end{array}$ & Figure 6 \\
\hline & CIE 3:9:12 & Summer 2015 & $\mathrm{~N}$ & $\begin{array}{l}\text { UTC: } \\
\text { 9:00 a.m. } \\
\text { 12:00 p.m. } \\
\text { 3:00 p.m. }\end{array}$ & Figure 7 \\
\hline \multirow{3}{*}{$\begin{array}{l}\text { CCT variability } \\
\text { depending on the } \\
\text { solar altitude }\end{array}$} & CIE 3:9:12 & 2015 & Patch 31-145 & $\begin{array}{l}\text { every } 2 \\
\text { minutes }\end{array}$ & Figure 8 \\
\hline & CIE 3:9:12 & $\begin{array}{l}\text { Summer } 2015 \\
\text { Winter } 2015\end{array}$ & Patch 31-145 & $\begin{array}{l}\text { every } 2 \\
\text { minutes }\end{array}$ & Figure 9 \\
\hline & CIE 3:9:12 & Summer 2015 & $\begin{array}{l}\mathrm{N} \\
\mathrm{S}\end{array}$ & $\begin{array}{l}\text { every } 2 \\
\text { minutes }\end{array}$ & Figure 10 \\
\hline SDPDs & CIE 3:12 & Summer 2015 & In $1^{\circ}$ steps & $\begin{array}{c}\text { UTC } \\
\text { 7:30 a.m.- } \\
\text { 8:30 a.m. }\end{array}$ & Figure 11 \\
\hline
\end{tabular}

\section{Results}

The key findings of the study are represented in a graphical summary of the CCT occurrence and CCT ranges corresponding to the fifteen CIE Standard Skies as well as of the CCT variability depending on the solar altitude. The practical implication of the CCT variability on the building level is graphically displayed through SDPDs. The parameters for each of the adopted scenarios can be found in Table 1.

\subsection{CIE sky type frequency distribution of occurrence}

Given the analysed datasets cover the period of January 1, 2015 to December 31, 2015, the dominant sky types resulting in CIE 3 for an overcast, CIE 9 for an intermediate and CIE 12 for a clear sky were selected. CIE 3 and CIE 12 are the most common sky types in Berlin. CIE 9 is 
predominant in the winter time of 2015. Further analysis presented in this paper draws upon the selected dominant skies shown in Figure 2. The results for the remaining twelve CIE sky types are available on request.
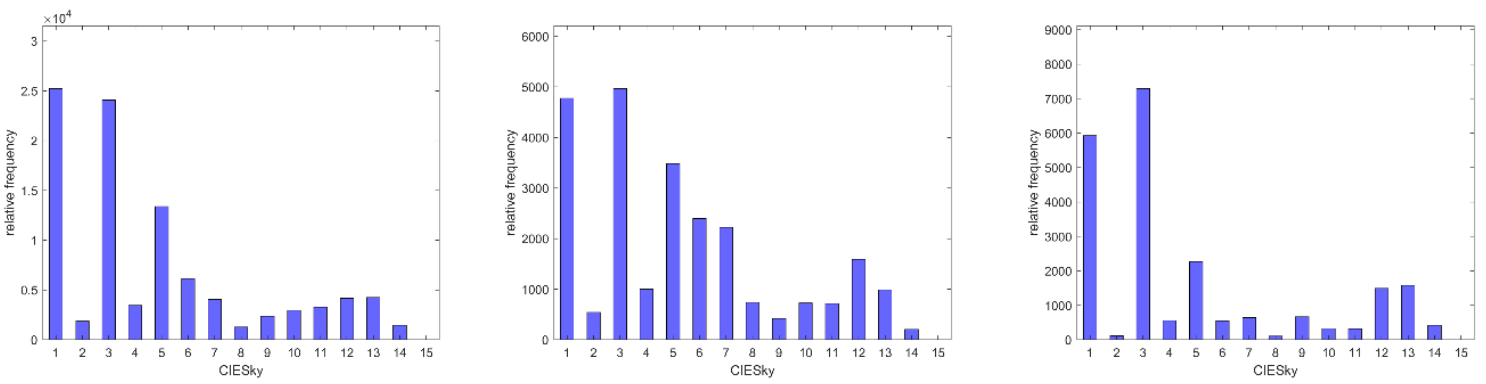

Figure 2 - CIE sky type occurrence for the whole year 2015 (left); for the summer period 2015 (middle); for the winter period 2015 (right)

\subsection{CCT frequency distribution of occurrence and CCT ranges}

In line with previous approaches, Figure 3 demonstrates the recorded CCT frequencies without differentiating between sky types (further referred to as 'mixed sky states'). It illustrates the CCT distribution depending on the period of time, the time of day, and the orientation. Changes in the CCT occurrence are primarily recognisable for different times of the day. Nonetheless, the predominant CCT interval did not vary much.
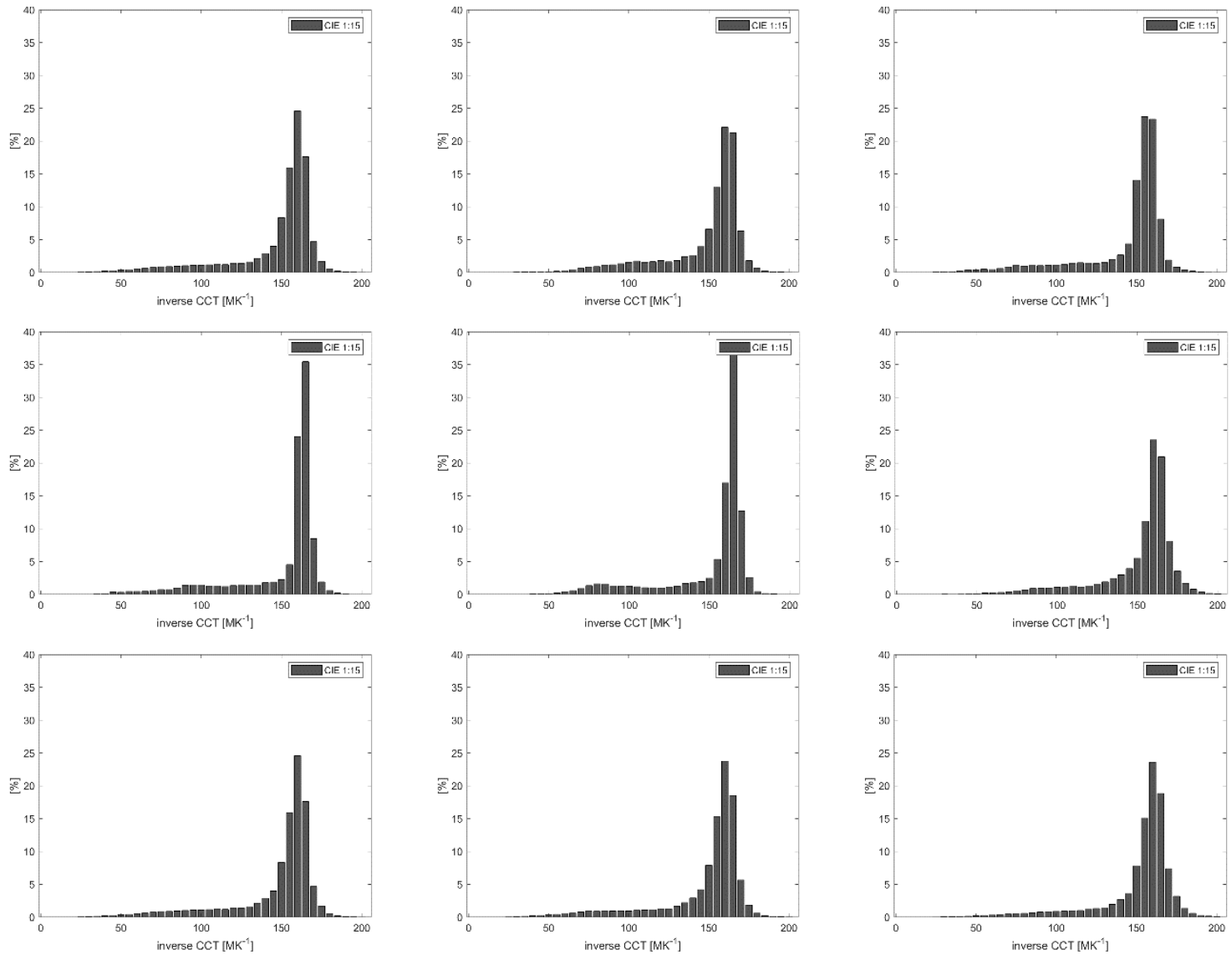

Figure 3 - Examples of CCT occurrences for mixed sky states depending on the period of time (2015 - top left, summer 2015 - top middle, winter 2015 - top right); the time of day (UTC 9:00 a.m. - centre left, 12:00 p.m. - centre middle, 3:00 p.m. - centre right), and the orientation (patches 31 - 145 - bottom left, patches $\mathrm{N}$ - bottom middle, patches $\mathrm{S}$ - bottom right) 
Further differentiation in CIE sky types revealed a strong variability in CCT occurrence and CCT ranges. CIE sky types $1-5$ representing the overcast sky conditions, which are the most common in Berlin (Figure 2), comply with the results for mixed sky states with a dominant CCT interval. However, the intermediate (CIE $6-10)$ and even more clearly the clear skies (CIE 11 -15) exhibit no evidently dominant CCT area, which could be averaged and represented in one value. The resulting CCT distributions are shown in Figure 4.

\section{CIE SKY TYPES}

overcast CIE $1-5$
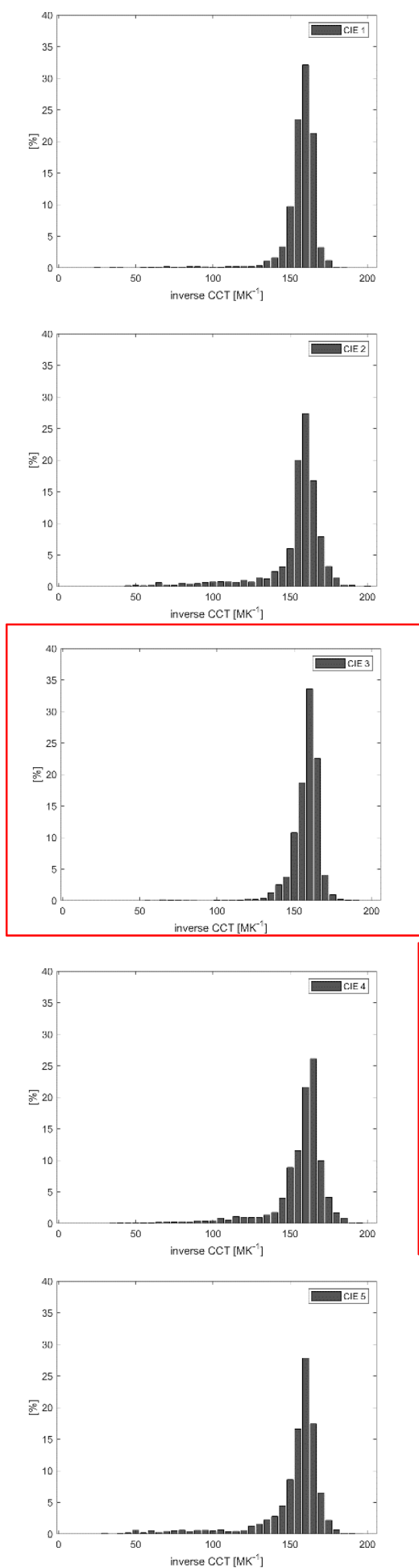

intermediate CIE $6-10$
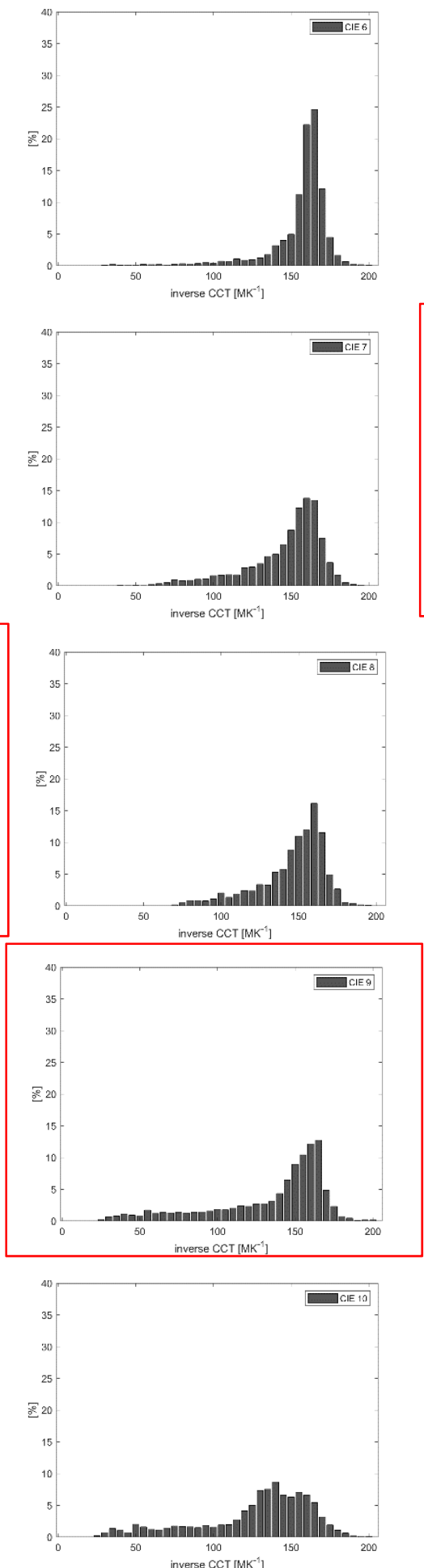

clear CIE $11-15$
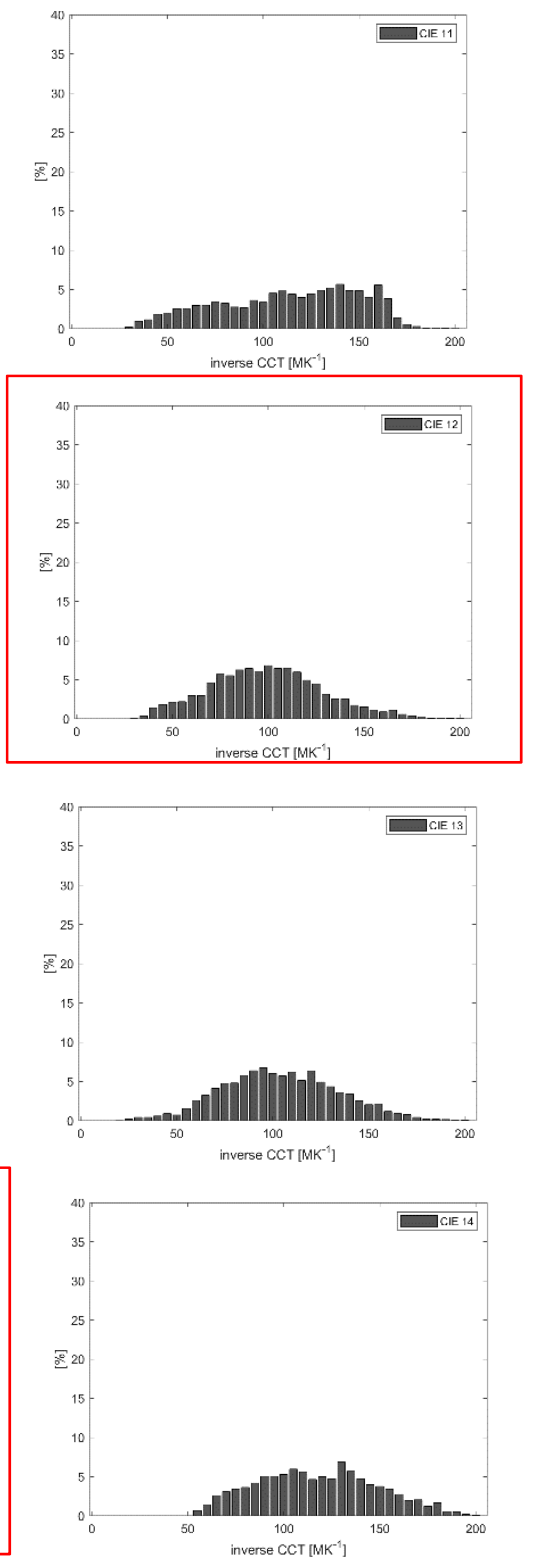

Figure 4 - Examples of CCT occurrences depending on CIE sky types 1 - 15 for the period of January 1, 2015 to December 31, 2015 
Further analysis revealed that the parameters period of time, orientation, and time of day affect both the CCT occurrence and CCT ranges for CIE 9 and CIE 12, but have no significant effect on the overcast sky, here represented with the CIE 3 . Figure 5 illustrates the distribution of the CCT as a function of seasonality. The classification displays a wider CCT range and higher CCTs reached in the winter time for both intermediate and clear skies. The distributions of the histograms in Figure 6 show the CCTs related to orientation. For intermediate skies the results indicate that the CCT range is wider and CCTs are higher for the north part of the hemisphere. Likewise, the CIE 12 sky boasts higher CCTs when only north patches are taken into account.

overcast CIE 3
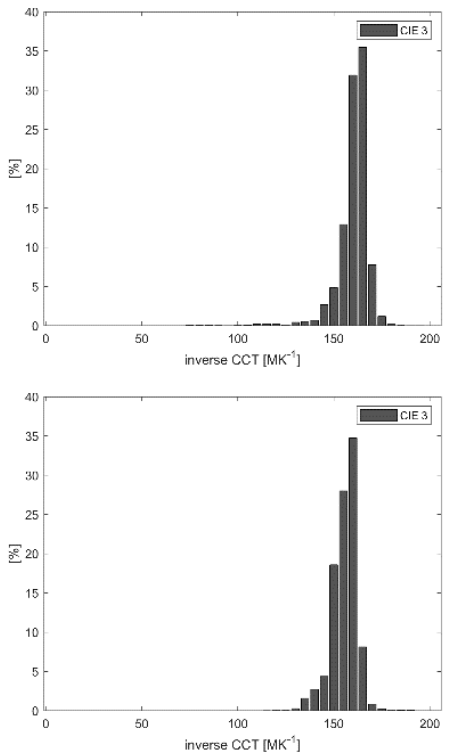

PERIOD OF TIME intermediate CIE 9
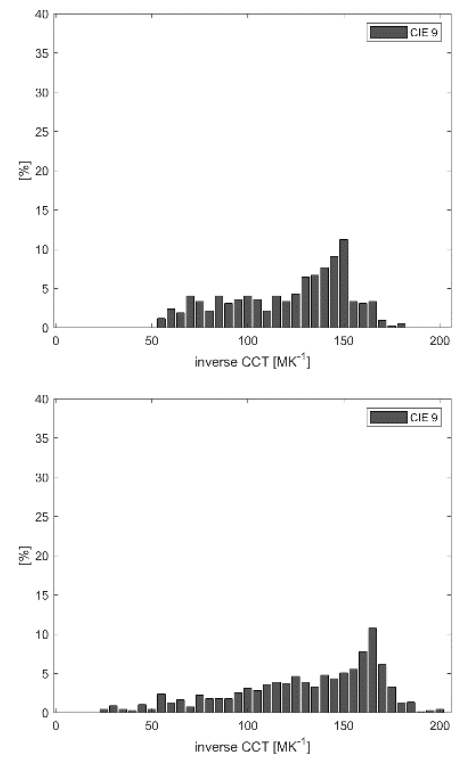

clear CIE 12
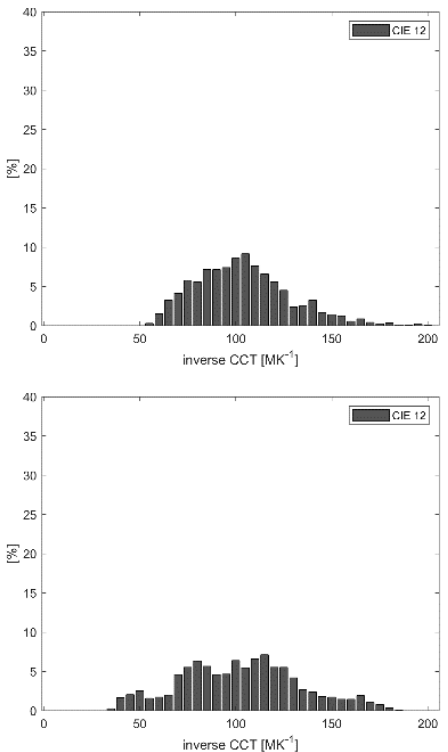

Figure 5 - Examples of CCT occurrences depending on the period of time for CIE sky types 3, 9, and 12 for summer 2015 (top), and winter 2015 (bottom)

overcast CIE 3
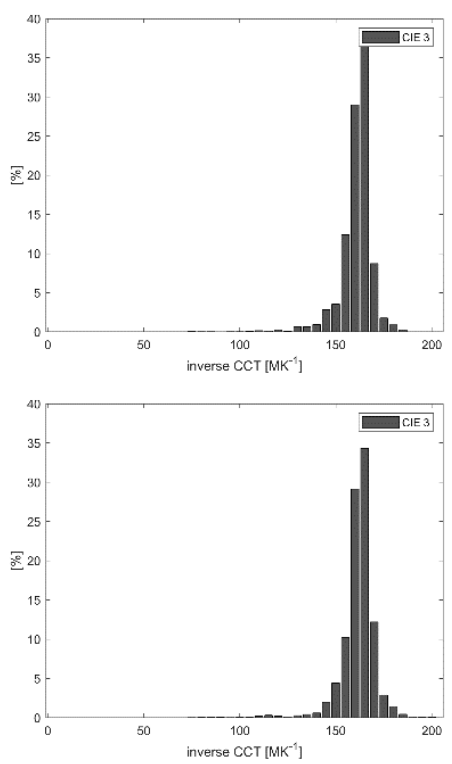

ORIENTATION intermediate CIE 9
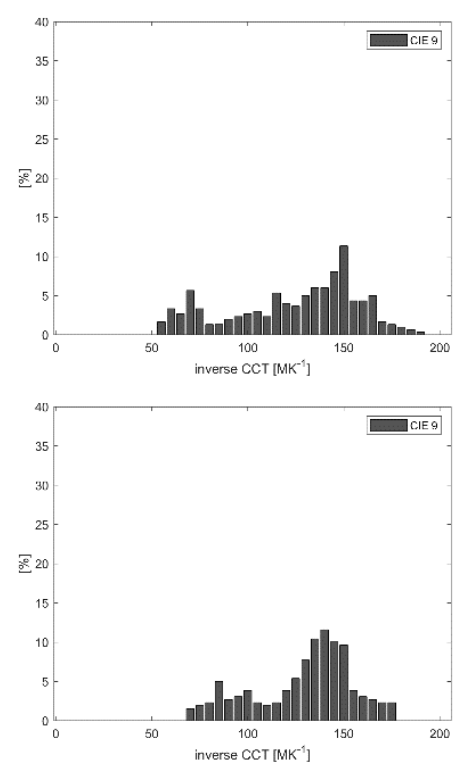

clear CIE 12
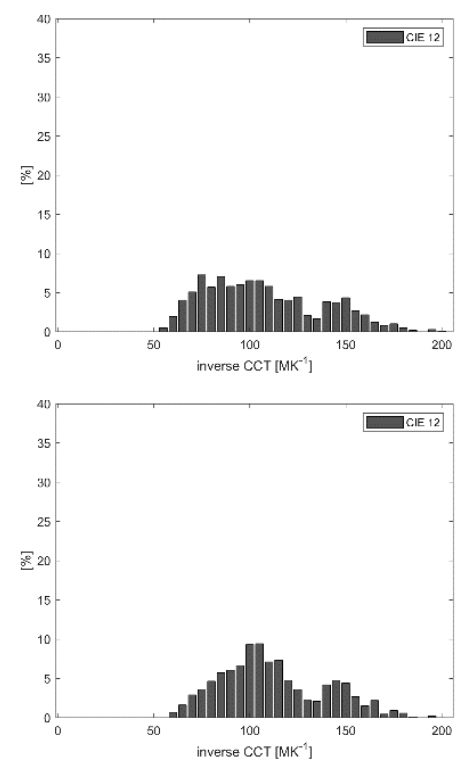

Figure 6 - Examples of CCT occurrences depending on the orientation for CIE sky types 3,9 , and 12 for the north (top) and the south parts of the hemisphere (bottom) 
In relation to diurnal changes described in Figure 7 a more dominating CCT area is recognisable around UTC 12:00 than during the two other times of the day set for this analysis, with a somewhat higher occurrence of the lower CCTs for CIE 9 and a marginally higher frequency of high CCTs for CIE 12. The results for the CCT occurrence suggest that assigning one CCT from a whole sky to the CIE sky types 9 and 12 would result in incorrect calculations. For CIE sky type 3 the differences in colour are negligible for all the three parameters and can therefore be expressed in an averaged CCT.

overcast CIE 3
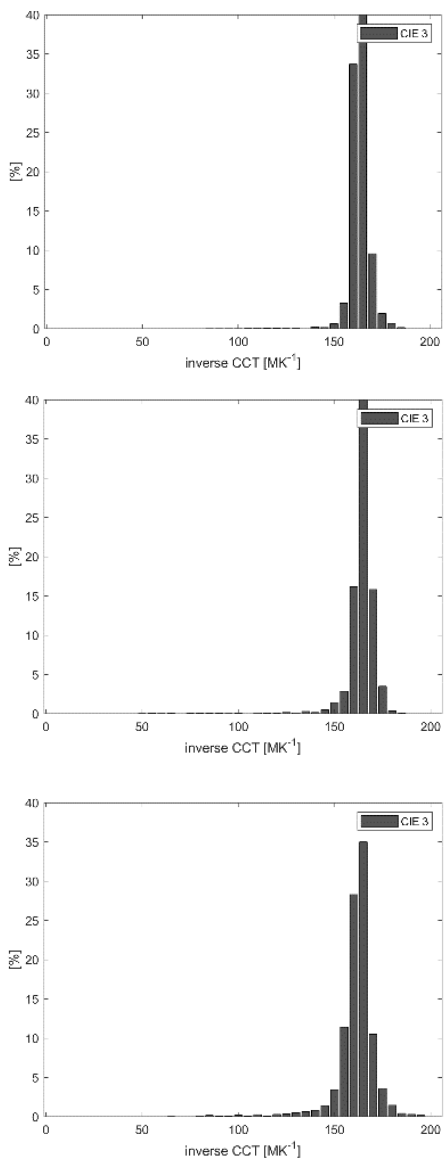

TIME OF DAY

intermediate CIE 9
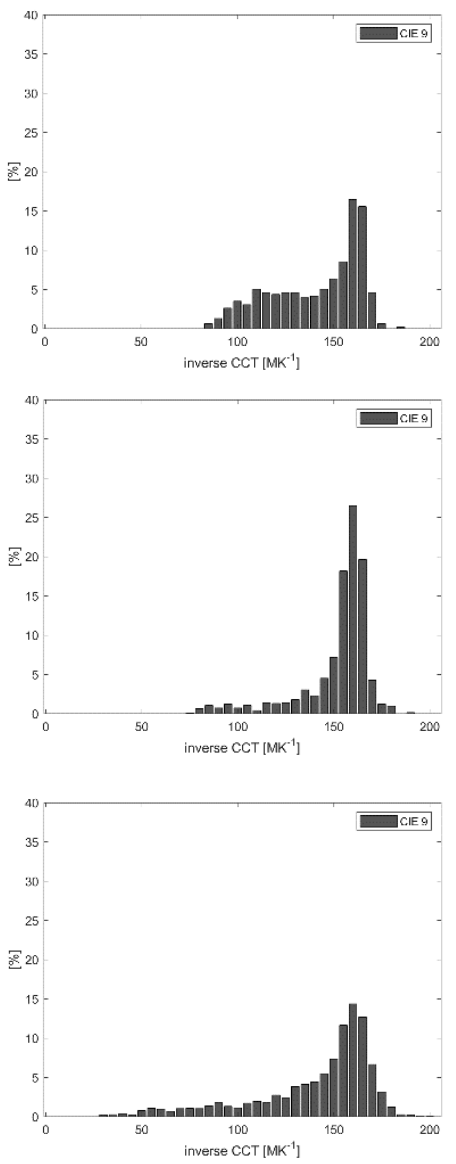

clear CIE 12
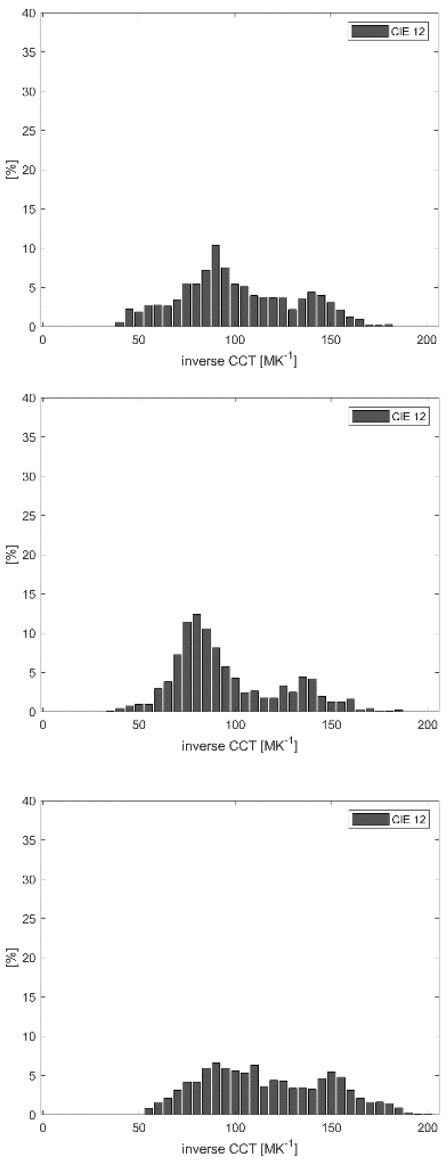

Figure 7 - Examples of CCT occurrences depending on the time of day for CIE sky types 3, 9, and 12 for UTC 9:00 a.m. (top), 12:00 p.m. (centre), and 3:00 p.m. (bottom)

\subsection{CCT variability depending on the solar altitude}

CIE 3

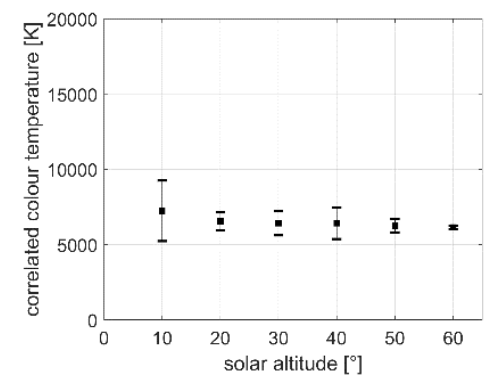

CIE SKY TYPE

CIE 9

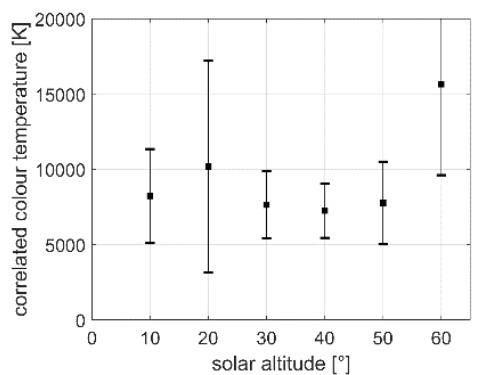

CIE 12

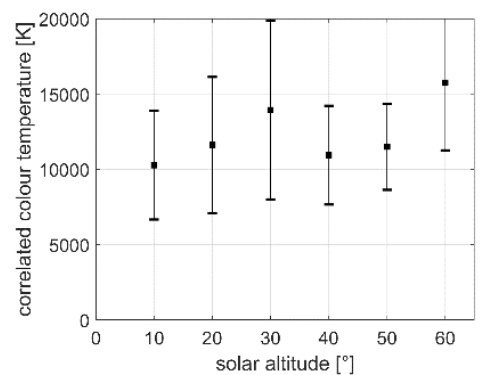

Figure 8 - Examples of mean CCTs and their standard deviations depending on the solar altitude for the CIE sky types 3 (left), 9 (middle), and 12 (right) 
Figures $8-10$ show changes in mean CCTs and their standard deviations in relation to the solar altitude $\left(10^{\circ}-60^{\circ}\right)$, taking account of the different CIE sky type, periods of time, and orientations respectively. The differences in CIE sky type highlighted that for solar altitudes higher $10^{\circ}$ mean CCTs for CIE 3 can be determined. However, the large deviations for CIE 9 and CIE 12 require further limitation of the influencing parameters. By limiting the period of time, the CCT variation for the CIE 3 is insignificant for all solar altitudes. For CIE 9, for solar altitudes higher $10^{\circ}$, the variability in CCT was significantly reduced for the winter season. CIE 12 reveals major discrepancies in CCTs for both seasons. By the restriction in orientation the limitation in CCT variability for the CIE 12 related to the south part of the hemisphere slightly improved.

CIE 3
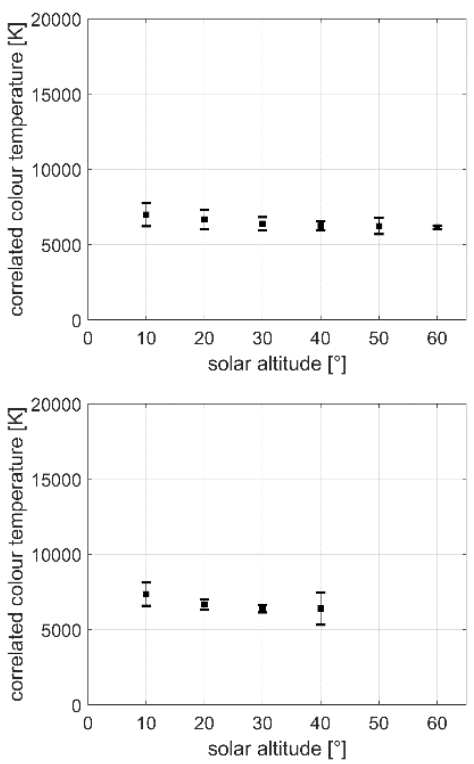

PERIOD OF TIME

CIE 9
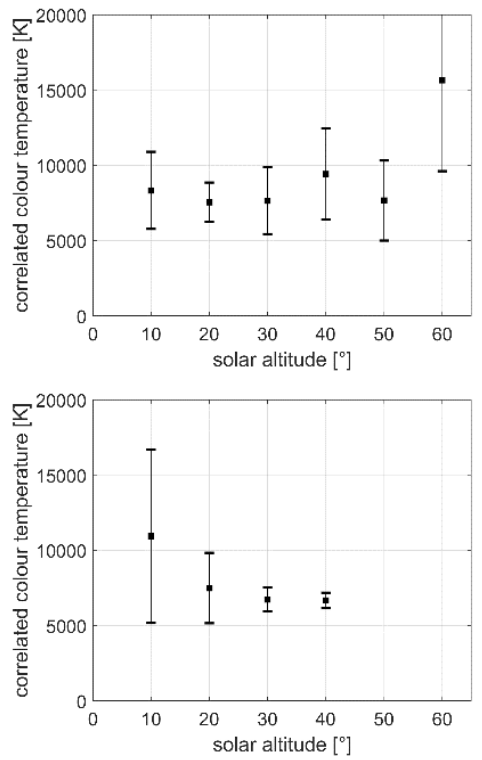

CIE 12
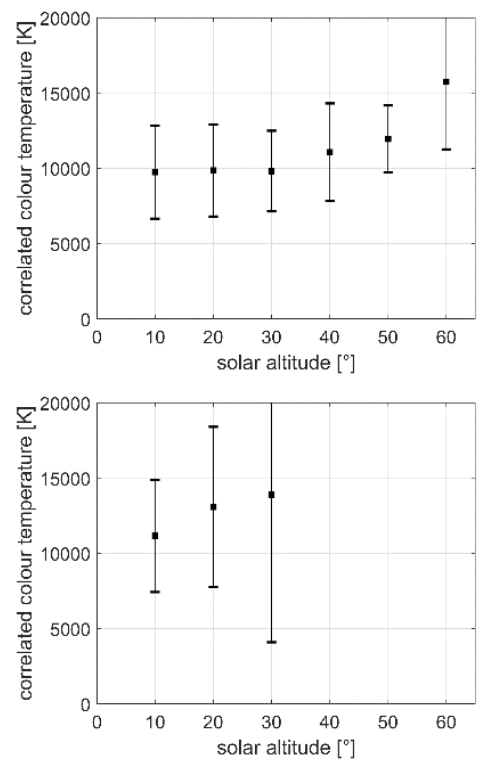

Figure 9 - Examples of mean CCTs and their standard deviations depending on the solar altitude for the periods of time summer 2015 (top) and winter 2015 (bottom)

CIE 3
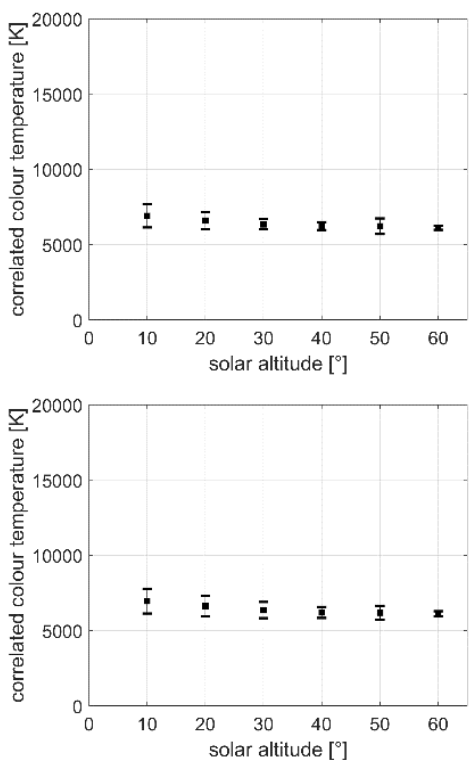

ORIENTATION

CIE 9
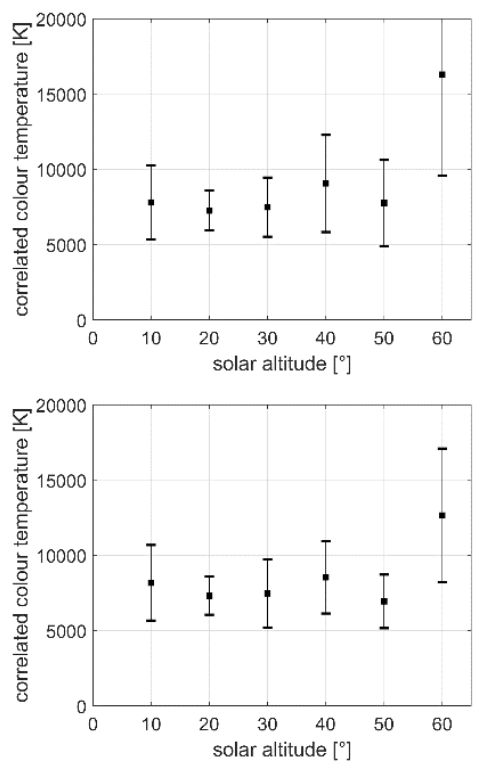

CIE 12
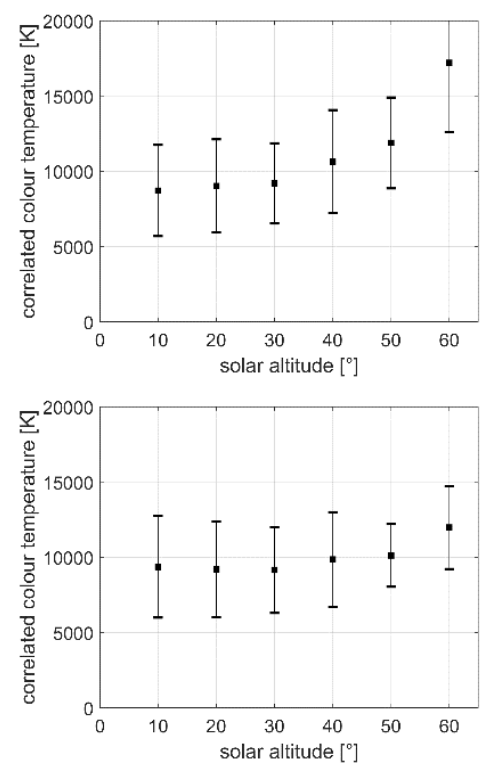

Figure 10 - Examples of mean CCTs and their standard deviations depending on the solar altitude for the orientations north (top) and south (bottom) 


\subsection{Exemplary spectral potential daylight diagrams}

Figure 11 illustrates the dynamic bandwidth of the CCT of façades in dependence of the sky type (CIE 3 and CIE 12), the orientation of the building (calculated in $1^{\circ}$ steps), the season (summer 01.06.2015-31.08.2015) and the time of day (UTC 7:30 a.m.-8:30 a.m., Berlin). The results for the SDPDs confirm a uniform CCT potential for an overcast sky but show an orientation dependent potential for a clear sky.
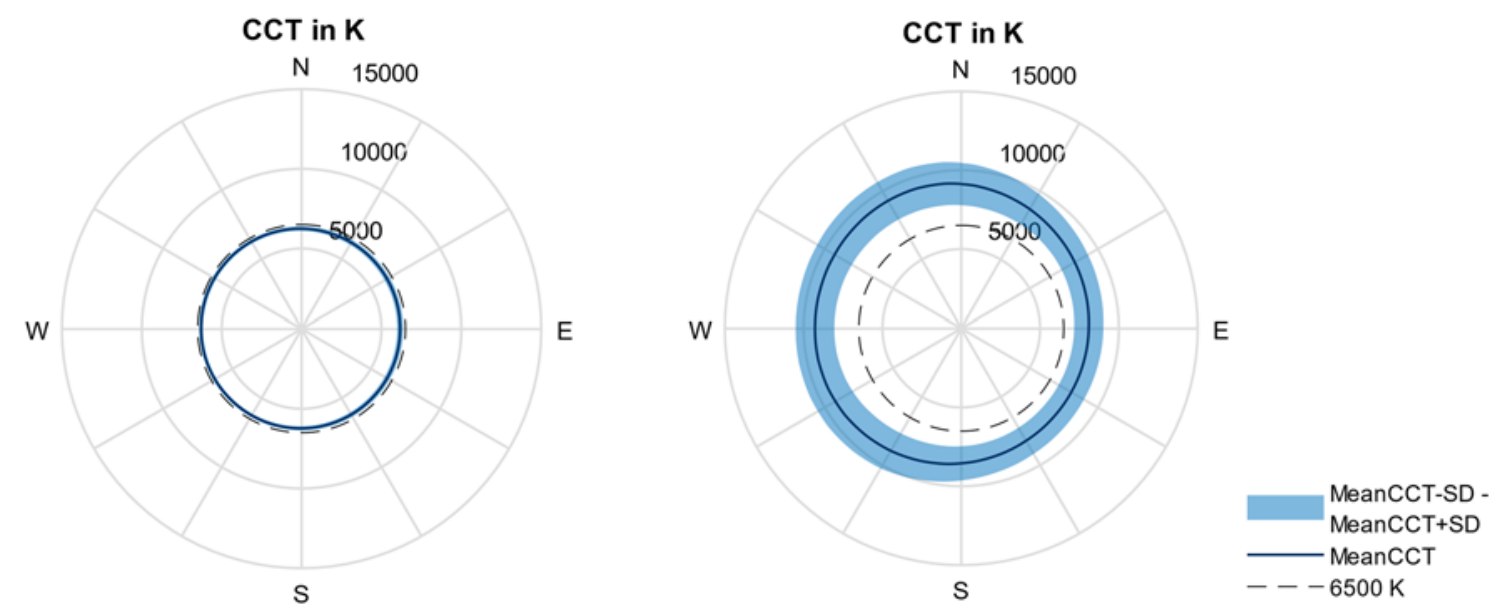

Figure 11 - Exemplary spectral potential diagrams for Berlin, 7:30 - 8:30 a.m. (UTC) for CIE 3 (left) and CIE 12 (right)

\section{Discussion and conclusions}

This paper offers a data-driven analysis of colorimetric characteristics of daylight in correspondence with standardised luminance sky types. To the authors best knowledge, this study is the first to both address the CCT occurrence, the CCT range, and the CCT variability depending on the solar altitude in relation to period of time, time of day, and orientation, corresponding to the fifteen CIE Standard General Skies and to investigate the effect of the variability of daylight on the colorimetric characteristics offered at the façade.

Prior work on colorimetric variability of daylight revealed that the underlying assumption that daylight can be described with the standard illuminant D65 is incorrect. Without differentiating between the sky types (Figure 3), our findings are in line with prior outcomes, suggesting that a dominating CCT region can be identified and what follows described by an average CCT. However, this might be caused either, if measured spatially resolved but without classifying in sky types, by the predominantly occurring overcast skies (Figure 2) or if measured globally by the dominating sunlight (Hernández et al. 2001-2). In this study the data has been collected spatially resolved and the calculated CCTs were categorised into the fifteen CIE Standard General Skies. The CCT frequency distribution for overcast skies are in good agreement with those presented by Hernández-Andrés et al. (2001-2) and Peyvandi et al. (2016). However, our findings extend the previous work, highlighting major colorimetric discrepancies particularly within the intermediate (CIE 6-10) and clear (CIE 11 - 15) sky types. We can therefore not support the results presented by Rusnák (2014) recommending average CCTs for the whole sky for the fifteen CIE Standard General Skies. The histograms showing the frequency distributions of occurrence confirm the hypothesis proposed by Collins (1965) to which the period of time, the time of day as well as the orientation are subject to colorimetric variability and affect both the CCT distribution and the CCT range. In addition, the effect of the solar altitude on CCT variability was confirmed for intermediate and clear skies, here represented in $\mathrm{CIE} 9$ and CIE 12 respectively, in relation to the above-mentioned parameters. The findings for

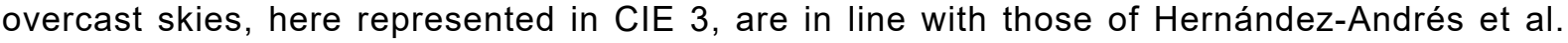
(2001-2) reporting no significant effect for solar altitudes higher than $10^{\circ}$. However, for the intermediate and clear skies further parameters need to be restricted in order to reduce the deviations. The statistical analysis of the spectral daylight potential represented by SDPDs confirms the hypothesis proposed in Diakite et al. (2018) according to which D65 can be assumed for an overcast sky in the planning process, however for clear skies the CCTs are significantly higher and depend on the orientation of the building and the solar altitude, here 
expressed in the time of day and season. In practical terms this means that daylight has a higher potential to induce the ipRGC influenced responses to light than is shown when calculating with the standard illuminant D65.

As noted beforehand, this is the first study to our knowledge to investigate the effect of seasonal, diurnal and directional changes on the colour of the sky in relation to the fifteen CIE Standard General Skies. It provides a framework for a colorimetric analysis and is the first step toward understanding the effect individual parameters have on the CCT variation. However, some limitations are noteworthy. Although our hypotheses were supported statistically, the sample data underlying the evaluation represents one location and the measurement period was restricted to one year, plus in this study the changes in spectral characteristics were not addressed. Future studies on colorimetric characteristics of daylight should additionally include geographic and atmospheric parameters to further the understanding of the variability in the colour of the sky for other locations. The findings show the colorimetric discrepancy both between and within the intermediate and clear sky types and support the key arguments against a fixed correlated colour temperature for those sky types, irrespective of whether the D65 or an averaged value. This study encompasses a CCT analysis from spectral sky measurement to colorimetric façade assessment and addresses the practical application of the analysis in the urban context.

\section{References}

CIE S 014-2/E:2006 ISO 11664-2:2007(E) Colorimetry - Part 2: CIE standard illuminants. Vienna. CIE Central Bureau

COLLINS, J.F. 1965. The colour temperature of daylight. Brit. J. Appl. Phys., 16, 527-532.

DIAKITE, A.K., KNOOP, M., 2018. Importance of Prevailing Sky Conditions and Building Orientation for the Assessment of Spectral Daylight Characteristics on Façades. In: Proceedings of PLEA 2018, Hongkong, China.

DIAKITE, A.K., KNOOP, M., 2019. Data-driven spectral sky models: A review. Journal of the International Colour Association, 23. 55-61

HENDERSON, S.T., HODGKISS, D. 1964. The spectral energy distribution of daylight. Brit. J. Appl. Phys., 15, 947-952.

HERNÁNDEZ-ANDRÉS, J., ROMERO, J., \& LEE, R.L. 2001-1. Colorimetric and spectroradiometric characteristics of narrow-field-of-view clear skylight in Granada, Spain. JOSA A, 18(2), 412-420.

HERNÁNDEZ-ANDRÉS, J., ROMERO, J., NIEVES, J.L., \& LEE, R.L. 2001-2. Color and spectral analysis of daylight in southern Europe. JOSA A, 18(6), 1325-1335.

KNOOP, M., ABDELMAGEED, A.A., LUO, T., WEBER, N. DIAKITE, A.K. 2017. Spatially resolved spectral sky daylight measurements data: Methods of collection, evaluation and representation. In: Proceedings of CIE 2017, Jeju, Korea. 1036-1046

KNOOP, M., WEBER, N. DIAKITE, A.K. 2019. Approach to analyze seasonal and geographical variations in daylight illuminants. To be published in the proceedings of CIE 2019

RUSNÁK, A. 2014. Meranie a hodnotenie spektrálnych charakteristík slnečného žiarenia (Measurements and evaluation of spectral sun radiation characteristics, Englische translation by Dr. Stanislav Darula). University of Technology in Bratislava, Faculty of Electrical Engineering and Information Technology

PEYVANDI, S., HERNÁNDEZ-ANDRÉS, J., OLMO, F.J., NIEVES, J.L., ROMERO, J. 2016, Colorimetric analysis of outdoor illumination across varieties of atmospheric conditions. JOSA A, 33(6), 1049-1059.

SASTRI, V.D P.; DAS, S R. 1971. Spectral distribution and colour of north sky at Bombay. J. Phys. D: Appl. Phys., 4, 381-386 